TITLE:

\title{
Involvement of activation-induced cytidine deaminase in the development of colitis-associated colorectal cancers.
}

\section{$\operatorname{AUTHOR}(\mathrm{S})$ :}

Endo, Yoko; Marusawa, Hiroyuki; Chiba, Tsutomu

\section{CITATION:}

Endo, Yoko ... [et al]. Involvement of activation-induced cytidine deaminase in the development of colitis-associated colorectal cancers.. Journal of gastroenterology 2011 , 46 Suppl 1: 6-10

\section{ISSUE DATE:}

2011-01

URL:

http://hdl.handle.net/2433/134798

\section{RIGHT:}

The final publication is available at www.springerlink.com; This is not the published version. Please cite only the published version.; この論文 は出版社版でありません。引用の際には出版社版をご確認ご利用くだ さい。 


\title{
Involvement of activation-induced cytidine deaminase (AID)
}

\section{in the development of colitis-associated colorectal cancers}

\author{
Yoko Endo, Hiroyuki Marusawa, and Tsutomu Chiba \\ Department of Gastroenterology and Hepatology, \\ Graduate School of Medicine, Kyoto University, Kyoto, Japan
}

\author{
Corresponding \& Reprint Author: Hiroyuki Marusawa at: \\ Department of Gastroenterology and Hepatology, \\ Graduate School of Medicine, Kyoto University, \\ 54 Kawara-cho, Shogoin, Sakyo-ku, Kyoto 606-8507, Japan \\ E-mail; maru@kuhp.kyoto-u.ac.jp \\ Phone; +81-75-751-4319 \\ Fax; $+81-75-751-4303$
}

Running Title: Involvement of AID expression in colitic cancer

Nonstandard abbreviations used: AID, activation-induced cytidine deaminase; TNF, tumor

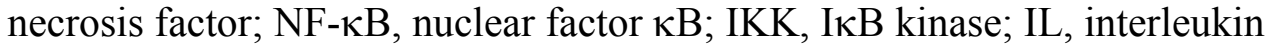
Keywords: AID, inflammatory bowel disease, colitis associated colorectal cancer, cytokine, TP53

No conflicts of interest exist. 
Chronic inflammatory bowel disease is an important etiologic factor in the development of colorectal cancer. The mechanism underlying the development of colorectal cancers through chronic inflammation, however, is not known. Activation-induced cytidine deaminase (AID) was originally identified as an inducer of somatic hypermutation in the immunoglobulin gene. We recently found that the mutagenic activity of AID expression links inflammation to the development of cancer. Aberrant AID expression is triggered by hepatitis $\mathrm{C}$ virus infection in human hepatocytes or Helicobacter pylori infection in human gastric epithelial cells and leads to the generation of somatic mutations in various tumor-related genes. Here, we review our findings of how AID contributes to the development of colitis-associated colorectal cancers. Immunohistochemistry revealed enhanced expression of endogenous AID protein not only in the inflamed colonic mucosa of ulcerative colitis patients, but also in tumor lesions of colitis-associated colorectal cancers. Pro-inflammatory cytokine TNF- $\alpha$ induced strong aberrant

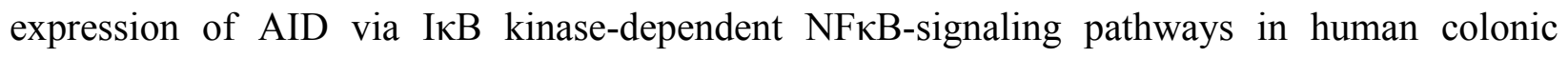
epithelial cells. Furthermore, AID expression was also elicited in response to the $\mathrm{T}$ helper cell-2-driven cytokines IL-4 and IL-13, which are activated in human inflammatory bowel disease. Aberrant activation of AID in colonic cells preferentially evoked genetic mutations in the TP53 gene, whereas there were no nucleotide alterations of the APC gene. These findings suggested that pro-inflammatory cytokine-mediated aberrant expression of AID in colonic epithelial cells plays a role as a genotoxic factor that enhances genetic instability during chronic colonic inflammation, leading to colitis-associated colorectal cancer development. 


\section{Introduction}

Inflammatory bowel disease (IBD) is an important etiologic risk factor for the development of colorectal cancer ${ }^{1}$. The relative risk of colorectal cancer in patients with ulcerative colitis (UC) is 20 times higher than that in the general population ${ }^{2}$. The cumulative risk of colitis-associated colorectal cancer (CAC) increases according to the number of years after the disease onset. The cumulative probability of cancer in patients with UC regardless of the disease extent is $2 \%$ at 10 years, $8 \%$ at 20 years, and $18 \%$ at 30 years $^{3}$. Patients with extensive colitis, colitis lasting 8 years or more, more severe inflammation, and early-age onset colitis have the greatest risk of developing cancer ${ }^{4}$. Recently, several studies showed that not only patients with UC but also those with Crohn's disease (CD) are at risk of developing colon cancer ${ }^{5}$. There is an 18 -fold increase in the risk of developing colorectal cancer in patients with $\mathrm{CD}$ compared with the general population ${ }^{6}$. The absolute cumulative risk frequency for developing colorectal cancer is $8 \%$ at 22 years from the onset of symptoms in patients with CD. Surveillance colonoscopy is frequently used to detect early cancer lesions in patients with IBD. Surveillance programs are not sufficiently effective to prevent cancers, however, because its diagnosis is difficult. To improve the detection of dysplastic lesions, the mechanisms by which chronic inflammation of the mucosa increases the risk of colorectal cancer development should be examined.

\section{Nucleotide-editing enzymes that can induce mutations in DNA}

CAC have several distinct characteristics compared with sporadic colorectal cancers. Adenomatous polyps are the major precursor of sporadic colorectal cancer and inactivation of the APC gene is known to be the initial event in many sporadic colorectal cancer, followed by changes in the K-ras, DCC, and TP53 genes ${ }^{7}$. In contrast, mutations in the TP53 gene are frequently found in early cancer development in UC patients and are already present in 
dysplastic lesions ${ }^{8,9}$. The molecular mechanisms underlying the development of the TP3 mutations in chronic inflamed mucosa that lead to carcinogenesis, however, are not known.

We recently demonstrated that the expression of activation-induced cytidine deaminase (AID), a DNA/RNA editing enzyme family member, links inflammation to the development of human gastrointestinal and hepatobiliary cancers ${ }^{10-12}$. AID is a member of the apolipoprotein B mRNA-editing catalytic subunit (APOBEC) family and deaminates cytidine (C) on target DNA to produce a thymidine (T), leading to the generation of changes in human genome DNA sequences ${ }^{13}$. Under physiologic conditions, AID can induce somatic hypermutation of immunoglobulin genes in activated B cells, which are essential for the diversification of antibody production. The fact that high AID expression levels are frequently observed in human lymphoid malignancies, however, suggests that inappropriate AID expression contributes to tumorigenesis due to its mutagenic activity ${ }^{14}$. Consistent with this hypothesis, a transgenic mouse model with constitutive and ubiquitous AID expression develops various tumors through the accumulation of somatic mutations in tumor-related genes ${ }^{15,} 16$. These findings suggest that aberrant AID expression acts as a genome mutator in non-lymphoid tissues and contributes to the development of cancer.

To clarify the role of AID in the development of gastrointestinal cancer, we first determined if there is a link between the regulation of AID expression in hepatocytes and the development of liver cancer ${ }^{11}$. Under physiologic conditions, AID expression is restricted to activated B cells, but we observed aberrant expression of AID in liver tissues exposed to chronic inflammation. Immunohistochemistry and real time-polymerase chain reaction (PCR) showed that AID expression is not normally detected in hepatocytes of noninflamed liver, but endogenous AID expression is significantly elevated in liver tissues with chronic hepatitis and liver cirrhosis. 
Moreover, aberrant AID expression is induced in response to pro-inflammatory cytokine stimulation or hepatitis $\mathrm{C}$ virus infection via the nuclear factor (NF)- $\mathrm{kB}$ signaling pathway in human hepatocytes ${ }^{12}$. Similarly, aberrant expression of AID is triggered by Helicobacter pylori infection or pro-inflammatory cytokine stimulation in human gastric epithelial cells ${ }^{10,17}$. We also found that endogenous expression of AID is elevated in bile ducts of primary sclerosing cholangitis, a representative chronic inflammatory disease in bile ducts, and AID expression is also induced after treatment with pro-inflammatory cytokines in human biliary cells ${ }^{18}$. These findings indicate that aberrant AID expression could be commonly induced in response to inflammatory stimulation in gastrointestinal epithelial cells.

\section{Pro-inflammatory cytokines are involved in the regulation of AID expression in human colonic epithelial cells}

To study the expression of AID protein in human colonic tissues, we performed immunohistochemistry in human colonic tissues from UC lesions, colitis-associated neoplasms, and nontumorous regions of patients with sporadic colon cancers. In normal colonic mucosa, no immunostaining for AID was observed. In contrast, in UC tissues, immunoreactivity for AID was detected in colonic epithelial cells as well as in infiltrating lymphocytes around the inflamed colonic mucosa $^{19}$. In the colitis-associated neoplasms, AID protein expression was also observed in neoplastic cells in the tumor lesions. These findings indicated that AID protein is expressed in the colonic epithelial cells that are chronically inflamed and in tumor cells of CAC.

To determine whether pro-inflammatory cytokines regulate AID transcription in human colonic epithelial cells, we analyzed the expression level of endogenous AID by quantitative reverse transcription-PCR and immunoblotting in cultured human colon cancer cells. First, we 
focused on tumor necrosis factor (TNF)- $\alpha$, which is constitutively activated in the colonic epithelial cells of patients with UC. Only a small amount of endogenous AID expression was detected in quiescent human colonic epithelial cells, but AID expression was markedly elevated after TNF- $\alpha$ treatment (Figure 1a). The transcription factor NF- $\mathrm{KB}$ is activated by TNF- $\alpha$ signaling. We therefore examined whether AID expression is regulated by the NF- $\mathrm{kB}$ signaling pathway in human colon cancer cells. Expression of the positive NF-кB regulators IKK $\alpha$, IKK $\beta$, and NF- $\mathrm{KB}$ itself resulted in an increased expression of endogenous AID protein (Figure 1b). A

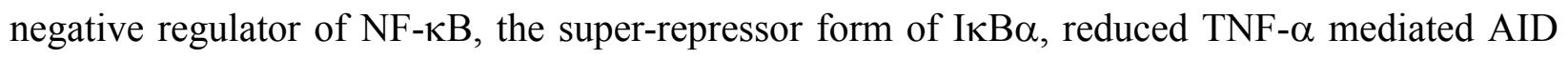
expression (Figure 1c). These findings support the idea that AID expression in colonic epithelial cells is regulated through the IKK-dependent NF- $\mathrm{KB}$ signaling pathway.

Thelper cell (Th) 2 cytokines also play an important role in the pathogenesis of UC. IL-4 and IL-13, which are involved in the Th2 cytokine response, share a common receptor unit and activate transcription factor STAT6 by phosphorylation to induce downstream signal transduction $^{20}$. AID is regulated by the IL-4/STAT6 signaling pathway in B lymphocytes ${ }^{21}$. This finding led us to test whether Th2 cytokines are also involved in the regulation of AID expression in colonic cells. Immunoblotting analysis revealed that IL-4 and IL-13 stimulation induced aberrant AID expression in cultured human colonic epithelial cells (Figure 2a, b). Further, small interference RNA specific for STAT6 suppressed IL-13-mediated AID expression (Figure 2b). These findings suggest that AID expression is regulated by IL-4 and IL-13 in a STAT6-dependent manner in human colonic epithelial cells.

On the other hand, Th1 cytokines are activated dominantly in the colonic epithelial mucosa of patients with $\mathrm{CD}$, and $\mathrm{CD}$ patients are also at high risk for developing colorectal cancer ${ }^{5}$. Interestingly, AID expression is upregulated in cultured colonic cells after treatment with the Th1 
cytokine IL-12 (Figure 2c). Thus, Th1 cytokines may also be involved in aberrant AID expression in human colonic epithelial cells.

\section{AID expression in colonic epithelial cells results in an accumulation of TP53 mutations}

The findings that AID expression is induced in colonic cells with chronic inflammation prompted us to examine whether aberrant AID expression could lead to the generation of somatic mutations in tumor-related genes in human colonic epithelial cells. We established a cultured human colonic cell line with constitutive AID expression using a retroviral system, and investigated the mutation frequencies in the TP53, APC, and K-ras genes of colonic epithelial cells in which AID was overexpressed for 8 weeks. No change or only a single nucleotide alteration was detected in all genes from cells transfected with control vectors. In contrast, however, several nucleotide alterations appeared in the TP53 gene after AID activation ${ }^{19}$ (Figure 3a). Mutation frequencies in the TP53 gene indicated that AID expression increased the mutations in a time-dependent manner (Figure 3b). In contrast to the TP53 gene, no nucleotide alterations were detected in the APC and K-ras genes, even after 8 weeks of AID activation. These findings indicate that aberrant AID expression in human colonic epithelial cells preferentially targets the TP53 gene and longer AID activation might induce more mutations. Why the TP53 gene is more sensitive to AID in human colonic epithelial cells remains unknown. Further studies are required to identify the specific target genes of AID in human colonic epithelial cells. Those genes may become new markers for predicting the development of CAC lesions.

\section{Conclusion}

The findings of the present study showed that pro-inflammatory cytokines, which play important roles in the pathphysiology of IBD, result in the aberrant expression of AID in human 
colonic epithelial cells, and lead to the generation of somatic mutations in the TP53 gene. This is new evidence that might link chronic inflammation of the colonic mucosa to the accumulation of TP53 mutations, leading to the development of colorectal cancer. 


\section{Figure legends}

Figure 1 AID expression is regulated by NF- $\kappa \mathrm{B}$ signaling in human colonic epithelial cells.

Quantitative PCR for the expression of AID $12 \mathrm{~h}$ after stimulation with TNF- $\alpha$. Immunoblot analysis was performed using anti-human AID antibody from cultured human colonic epithelial cells transfected with expression vector encoding IKK $\alpha$, IIK $\beta, \mathrm{NF}-\kappa \mathrm{B}$, or control vector (lower panel). Cells were transfected with a vector for the expression of the super-repressor form of $\mathrm{I} \kappa \mathrm{B} \alpha(\mathrm{I} \kappa \mathrm{B} \alpha \Delta \mathrm{N})$ or with a control vector, followed by stimulation with TNF- $\alpha$ for $12 \mathrm{~h}$. Quantitative PCR of AID expression was performed using each specimen as a template (lower panel).

Figure 2 Regulation of AID expression by Th2 and Th1 cytokine stimulation in human colonic cells.

(a) Cells were treated with IL-4 for the indicated times. Total lysates were subjected to immunoblotting using anti-AID (upper panel), anti-phosphorylated STAT6 (middle panel), or anti- $\alpha$-tubulin (lower panel). (b) Immunoblot analysis was performed using anti-human AID antibody after IL-3 treatment with or without STAT6 small interference RNA. (c) Quantitative PCR analyses for AID expression in cells treated with IL-12 and interferon- $\gamma$.

Figure 3 Mutation frequencies in various tumor-related genes in cultured human colonic epithelial cells with AID activation. (a) Each tumor related gene was amplified by reverse transcription-PCR from cells with 8 weeks of AID activation, the PCR products were subcloned and sequence analyses were performed. Mutation frequencies were calculated per total bases. (b) Mutation frequencies in the TP53 gene from cells at 2, 4, 8weeks after AID expression compared with control cells. 


\section{References}

1. Podolsky DK. Inflammatory bowel disease. N Engl J Med 2002;347:417-29.

2. Mellemkjaer L, Olsen JH, Frisch M, Johansen C, Gridley G, McLaughlin JK. Cancer in patients with ulcerative colitis. Int J Cancer 1995;60:330-3.

3. Eaden JA, Abrams KR, Mayberry JF. The risk of colorectal cancer in ulcerative colitis: a meta-analysis. Gut 2001;48:526-35.

4. Lennard-Jones JE, Morson BC, Ritchie JK, Williams CB. Cancer surveillance in ulcerative colitis. Experience over 15 years. Lancet 1983;2:149-52.

5. Jess T, Gamborg M, Matzen P, Munkholm P, Sorensen TI. Increased risk of intestinal cancer in Crohn's disease: a meta-analysis of population-based cohort studies. Am J Gastroenterol 2005;100:2724-9.

6. Gillen CD, Walmsley RS, Prior P, Andrews HA, Allan RN. Ulcerative colitis and Crohn's disease: a comparison of the colorectal cancer risk in extensive colitis. Gut 1994;35:1590-2.

7. Fearon ER, Vogelstein B. A genetic model for colorectal tumorigenesis. Cell 1990;61:759-67.

8. Yin J, Harpaz N, Tong Y, Huang Y, Laurin J, Greenwald BD, Hontanosas M, Newkirk C, Meltzer SJ. p53 point mutations in dysplastic and cancerous ulcerative colitis lesions. Gastroenterology 1993;104:1633-9.

9. Kern SE, Redston M, Seymour AB, Caldas C, Powell SM, Kornacki S, Kinzler KW. Molecular genetic profiles of colitis-associated neoplasms. Gastroenterology 1994;107:420-8.

10. Matsumoto Y, Marusawa H, Kinoshita K, Endo Y, Kou T, Morisawa T, Azuma T, Okazaki IM, Honjo T, Chiba T. Helicobacter pylori infection triggers aberrant expression of activation-induced cytidine deaminase in gastric epithelium. Nat Med 2007;13:470-6.

11. Kou T, Marusawa H, Kinoshita K, Endo Y, Okazaki IM, Ueda Y, Kodama Y, Haga H, Ikai I, Chiba T. Expression of activation-induced cytidine deaminase in human hepatocytes during hepatocarcinogenesis. Int J Cancer 2007;120:469-76.

12. Endo Y, Marusawa H, Kinoshita K, Morisawa T, Sakurai T, Okazaki IM, Watashi K, Shimotohno K, Honjo T, Chiba T. Expression of activation-induced cytidine deaminase in human hepatocytes via NF-kappaB signaling. Oncogene 2007;26:5587-95.

13. Muramatsu M, Kinoshita K, Fagarasan S, Yamada S, Shinkai Y, Honjo T. Class switch recombination and hypermutation require activation-induced cytidine deaminase (AID), a potential RNA editing enzyme. Cell 2000;102:553-63.

14. Kinoshita K, Nonaka T. The dark side of activation-induced cytidine deaminase: relationship with leukemia and beyond. Int J Hematol 2006;83:201-7.

15. Okazaki IM, Hiai H, Kakazu N, Yamada S, Muramatsu M, Kinoshita K, Honjo T. Constitutive expression of AID leads to tumorigenesis. J Exp Med 2003;197:1173-81.

16. Morisawa $\mathrm{T}$, Marusawa $\mathrm{H}$, Ueda $\mathrm{Y}$, Iwai A, Okazaki IM, Honjo $\mathrm{T}$, Chiba $\mathrm{T}$. Organ-specific profiles of genetic changes in cancers caused by activation-induced cytidine deaminase expression. Int J Cancer 2008;123:2735-40.

17. Chiba T, Marusawa H, Seno H, Watanabe N. Mechanism for gastric cancer development by Helicobacter pylori infection. J Gastroenterol Hepatol 2008;23:1175-81.

18. Komori J, Marusawa H, Machimoto T, Endo Y, Kinoshita K, Kou T, Haga H, Ikai I, Uemoto S, Chiba T. Activation-induced cytidine deaminase links bile duct inflammation 
to human cholangiocarcinoma. Hepatology 2008;47:888-96.

19. Endo Y, Marusawa H, Kou T, Nakase H, Fujii S, Fujimori T, Kinoshita K, Honjo T, Chiba T. Activation-induced cytidine deaminase links between inflammation and the development of colitis-associated colorectal cancers. Gastroenterology 2008;135:889-98, 898 e1-3.

20. Hebenstreit D, Wirnsberger G, Horejs-Hoeck J, Duschl A. Signaling mechanisms, interaction partners, and target genes of STAT6. Cytokine Growth Factor Rev 2006; 17:173-88.

21. Dedeoglu F, Horwitz B, Chaudhuri J, Alt FW, Geha RS. Induction of activation-induced cytidine deaminase gene expression by IL-4 and CD40 ligation is dependent on STAT6 and NFkappaB. Int Immunol 2004;16:395-404. 
Figure 1

a

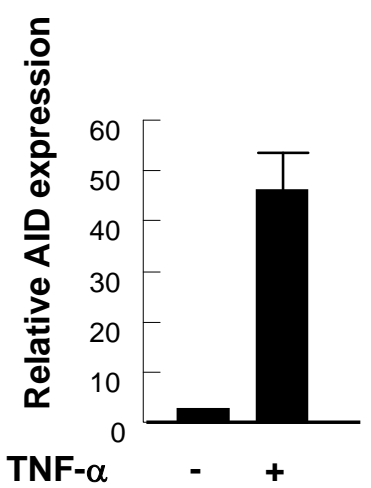

b
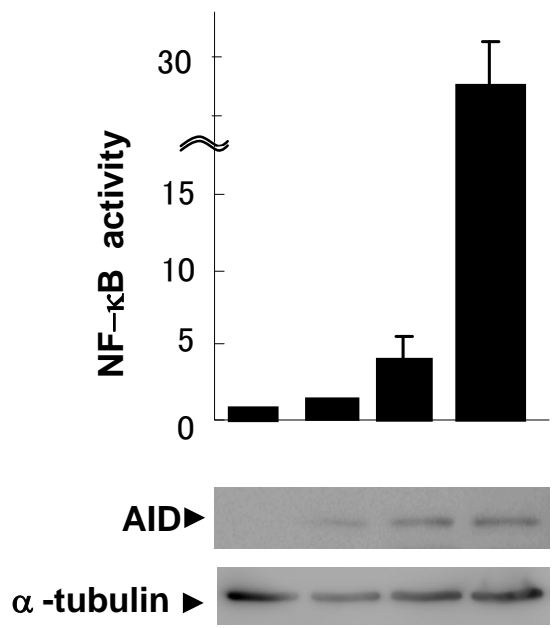

CTR IKK $\alpha$ IKK $\beta$ NF- $\kappa B$

C

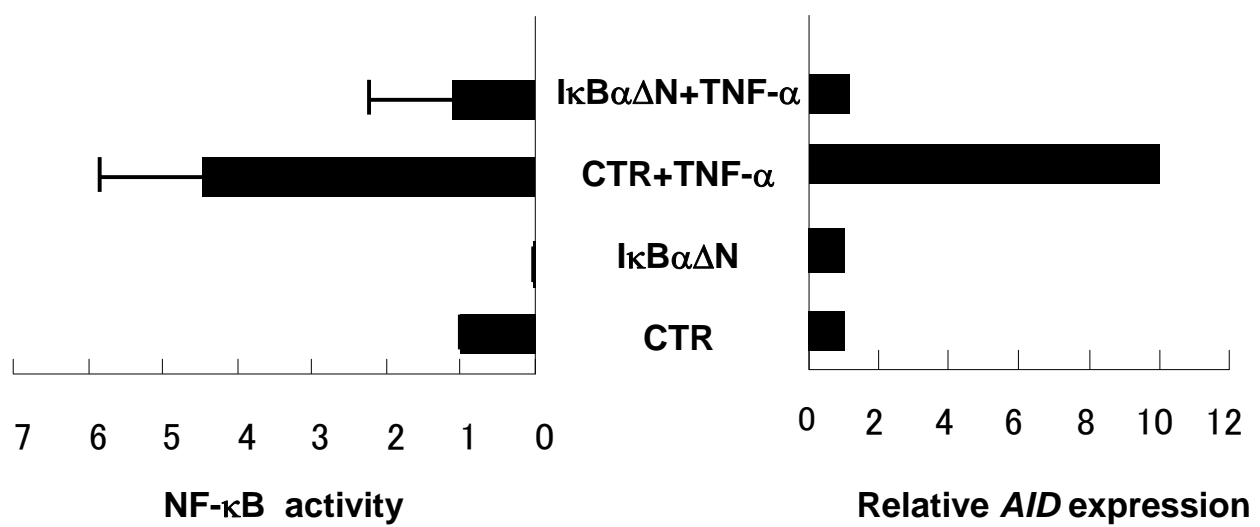


Figure 2

a

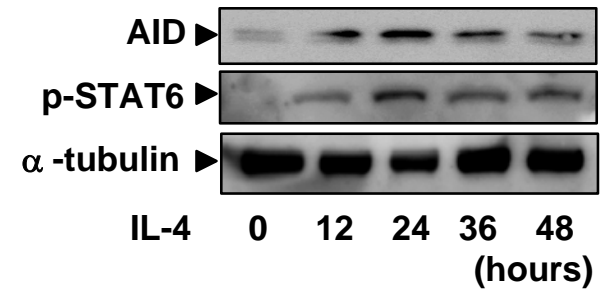

b

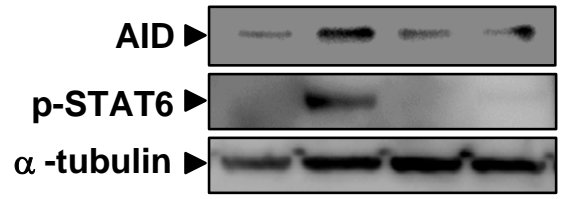

IL-13 (-) (+) (-) (+)

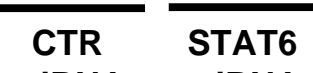

-siRNA -siRNA

C

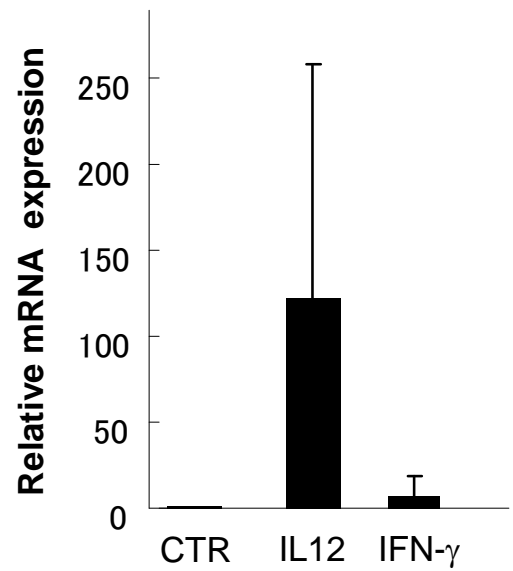




\section{Figure 3}

a

\begin{tabular}{lcc}
\hline Target Genes & $\begin{array}{r}\text { Mutation number } \\
\text { (n / total bases) }\end{array}$ & $\begin{array}{c}\text { Mutation Frequencies } \\
(/ 10000 \mathrm{bp})\end{array}$ \\
\hline TP53 & $7 / 26,400$ & 2.27 \\
APC & $0 / 23,425$ & 0 \\
K-ras & $0 / 18,760$ & 0 \\
\hline
\end{tabular}

b

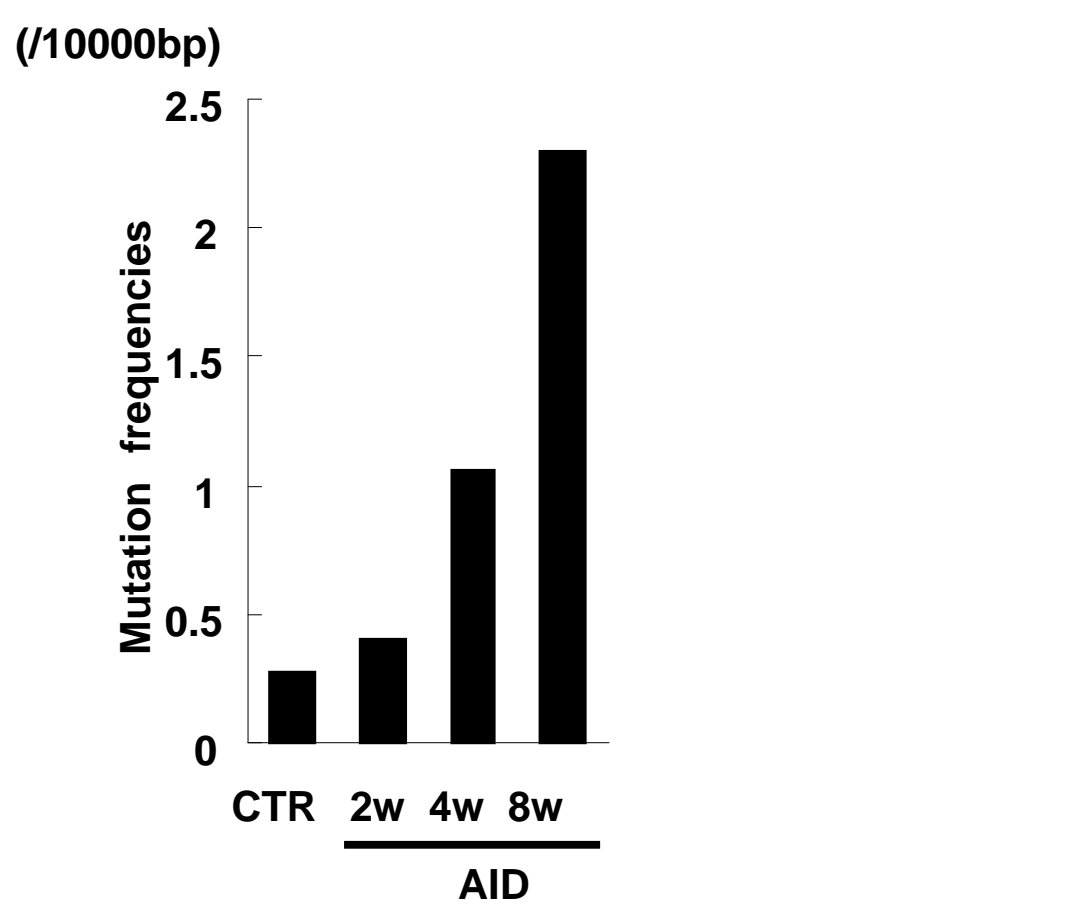

